\title{
Identifying and realising the benefits of smart infrastructure and construction
}

David Pocock MA, CEng, FICE, MIAM

Senior Director, Strategic Consulting, Jacobs, UK

(david.pocock@jacobs.com)

The Centre for Smart Infrastructure and Construction at Cambridge University in the UK is developing and demonstrating an exciting range of applications of 'smart' technology applications in infrastructure and construction. Infrastructure developers, operators and users face a wide range of risks, to which the centre's achievements can be applied, yielding valuable benefits throughout the continuous asset lifecycle. Benefits are derived in the design phase by avoiding over-design; in the construction phase by validating as-built quality and performance; and in the operational phase by better use of existing assets, diagnosis of cracking, and intelligent assets that sense and respond to their own condition. This paper identifies how are derived through direct cost savings and a wide range of potential indirect routes, both to developers and managers of existing assets, and ultimately to the end users. Most of the indirect benefits can also be monetised to some extent, to compare with the cost of the intervention as benefit:cost ratios. Further possibilities exist for avoiding costs in service through combining smart technology with engineering knowledge of the expected behaviour, deterioration and failure patterns of assets in service.

\section{Notation}

CA estimated cost avoided as a direct result of a proactive maintenance action

OI operational impact if failure had occurred

$\mathrm{R} \quad$ cost of reactive work not required

$\mathrm{P} \quad$ cost of planned and scheduled repair

\section{Introduction}

\subsection{Strategic objective}

The current UK infrastructure situation may be characterised as comprising extensive existing assets, many of which are relatively aged, with relentlessly rising demand for capacity and availability, inevitably constrained funding and a complex landscape for potential new-build projects. In this context, there is an opportunity to apply smart infrastructure and construction techniques, to the benefit of asset users, by enabling savings in construction and/or during the lifecycle as well as maintaining or enhancing safety. However, despite the range and demonstrated effectiveness of smart infrastructure and construction techniques emerging, the uptake so far seems to be modest; there is a need to increase uptake and part of the solution appears to be the provision of clearer, more compelling business cases articulating the modest additional investment required and the benefits expected to be realised. Hence this paper aims to help the developers of smart infrastructure technology to generate compelling business cases for their solutions.

\subsection{Centre for Smart Infrastructure and Construction (CSIC)}

The Centre for Smart Infrastructure and Construction (CSIC) at Cambridge University in the UK is developing and demonstrating an exciting range of 'smart' technology applications in infrastructure and construction. Infrastructure developers, operators and users face a wide range of risks, to which the CSIC achievements can be applied, yielding valuable benefits throughout the continuous asset lifecycle (CSIC, 2019). Benefits are derived in the design phase by avoiding over-design; in the construction phase by validating as-built quality and performance; or in the operational phase by better use of existing assets, diagnosis of cracking, or intelligent assets that sense and respond to their own condition.

At several CSIC events and steering group meetings, the importance of business cases has been discussed. This paper, by a steering board member, aims simply to assist with that need, by identifying potential sources of value or benefit, and summarising examples of how some CSIC achievements to date create benefit. It is hoped that this framework may assist with business case development, and also for taking stock of achievements so far and looking for further opportunities or 'routes to market'.

\section{Infrastructure clients}

Benefits are derived through direct cost savings or a number of indirect routes, both to developers and managers of existing assets. Most of the indirect benefits can be monetised to some extent, to compare with the cost of the intervention as benefit:cost ratios, for business cases or prioritisation. Most infrastructure clients are already managing existing assets when they develop projects (ICE, 2013). They use their existing assets to serve their clients (i.e. the asset users, sometimes referred to as the 'ultimate customers'). It is important to recognise that project clients are asset managers who undertake large or small projects from time to time as part of the asset management lifecycle of their asset portfolios, rather than only think of them as developers of new assets. This is done to ensure that the ultimate customers' needs continue to be served in the face of rising demand or falling asset performance. 
Smart Infrastructure and Construction

Volume 172 Issue 4
Identifying and realising the benefits of smart infrastructure and construction Pocock
The ultimate customers may well be those who realise some or all of the benefits, particularly the non-monetary benefits, as opposed to the project clients or participants, and this requires a longer-term benefits assessment when making the case for additional short-term expenditure to enable smart capabilities to be incorporated.

\section{Framework for sources of benefit}

\subsection{Proposed framework}

The simple framework for potential benefits is proposed in Figure 1, the elements of which are described in the following sections.

\subsection{Direct cost savings}

Direct cost savings may arise from the following sources.

\subsubsection{Reduced capital costs}

The following are examples of potential direct capital expenditure ('capex') cost savings.

- simpler design, cheaper to produce

- less land-take or site footprint so less costs of site establishment

- reduced temporary works

घ good planning enabling "right-first-time" construction, and hence less re-work

- less contract penalty costs from over-runs

a cheaper finance or shorter period to finance

v cheaper insurance or shorter period to insure

\subsubsection{Reduced operational cost}

The following are examples of potential direct operational expenditure ('opex') savings.

- less breakdowns or failures, leading to reduced reactive maintenance costs

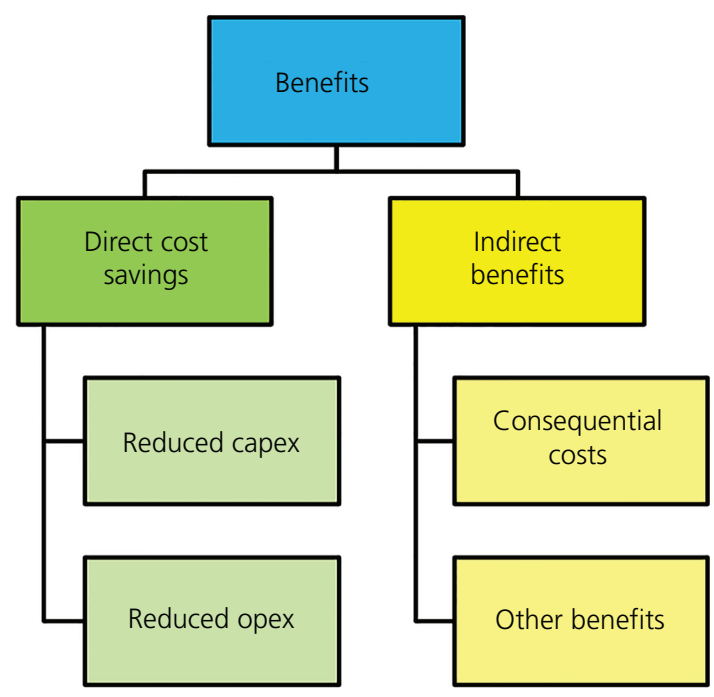

Figure 1. Proposed benefits framework
- early detection of deterioration condition, leading to savings in reactive maintenance, as described further in Section 6 below, "Cost avoidance".

- design for ease of inspection and maintenance, leading to reduced planned maintenance costs

- smaller operation and maintenance (O\&M) teams arising from the above

- holding and/or consuming less spares

- better information management and handover, avoiding resurvey of lost information

- less "paperwork", more automation

- less penalties from non-availability, or shortfalls in capacity or product quality

- reduced sinking funds for future costs

- cheaper insurance, through the ability to demonstrate safer working practices

\subsection{Indirect benefits}

Indirect benefits may arise from the following sources.

- Consequential cost savings such as those realised by asset users (e.g. from reduced traffic queues or train delays or cancellations)

- Safety: less risk of harm to humans

- Security: reduced threat to systems for immigration, defence, commercial, personal data

- Quality: effective planning leading to the right quality the first time, in construction, O\&M or service to customers

- Time: on-time delivery of construction, O\&M or service to customers

- Availability: assets available for use when needed

- Resilience: capacity for future demand growth or extreme events, or ability to recover

- Carbon dioxide: energy and emissions reduction across the lifecycle

- Environment: less risk of harm (e.g. to air quality, flora, fauna); reduced waste

- Heritage: less risk of harm to heritage assets

- Reputation: stakeholder confidence (e.g. regulators, investors, voters, tenants); less risk of harm to business relationships and "goodwill"

- Assurance: all-round confidence/evidence, the organisation can "sleep at night"

- Wider economic/social benefits arising from the above (Anderson, 2018)

These can be harder to put financial figures to, but there is important guidance for this in the HM Treasury "Green Book" appraisal guidance (Treasury, 2020).

\section{Examples of how smart infrastructure solutions deliver benefits}

4.1 Applying the framework

The CSIC achievements can be reviewed in the framework described above, as illustrated by examples in Table 1 and the subsequent brief descriptions below. 


\subsection{Avoiding over-design}

In the design phase, CSIC has demonstrated ("Staffordshire bridges") that sensing can be applied to establish how much of an element is actually working structurally, and hence how much the element could be safely reduced or simplified to economise in repeat construction, with associated potential for a shorter programme, and consumption of less energy (CSIC, 2018). A similar rationale applies to the CSIC project that demonstrated the ability to simplify design of nodes between main tunnels and cross-passages (CSIC, 2017). Thus, there is a direct capital cost benefit, as well as indirect benefits in time and carbon dioxide emissions. With shorter programmes, there are potential secondary benefits such as less risk of accidents during construction and earlier opportunity for users of the asset to derive in-service benefits. While saving initial cost, this removes the potential longer-term value of spare capacity and hence in-built resilience to future growth in demand. The latter point contrasts with some early engineering pioneers who may have built more on the basis of engineering judgement in the absence of codes, and thereby provided spare capacity that has been valuable to accommodate the demand growth of the modern era.

\subsection{Validating as-built quality and performance}

In the construction context, CSIC has demonstrated that sensing can be applied to check as-constructed quality and performance, for example, pile and diaphragm wall integrity testing at Battersea (CSIC, 2016), load uptake in major in situ piles (CSIC, 2017), or strain distribution around side-passage connections in tunnels at Liverpool Street station (CSIC, 2017), in each case providing value through confidence in compliance or improved understanding of behaviour. This avoids uncertainty risks and also the potential "capex" risks of re-work costs and associated delays, by detecting concerns earlier and enabling earlier resolution. There are also potential benefits in programme saving through quicker validation, and safety from reduced activity by persons on site.

Table 1. Examples of CSIC project benefits created

\begin{tabular}{|c|c|c|c|c|}
\hline Phase & Principle & Capex & Opex & Indirect \\
\hline Design & $\begin{array}{l}\text { Avoiding } \\
\text { over- } \\
\text { design }\end{array}$ & $\checkmark$ & & $\begin{array}{l}\text { Time, carbon dioxide } \\
\text { reduction }\end{array}$ \\
\hline Construction & $\begin{array}{l}\text { Validating } \\
\text { as-built } \\
\text { quality }\end{array}$ & $\checkmark$ & & $\begin{array}{l}\text { Safety, time, } \\
\text { assurance }\end{array}$ \\
\hline Operation & $\begin{array}{l}\text { Masonry } \\
\text { arch } \\
\text { diagnostics }\end{array}$ & & $\checkmark$ & $\begin{array}{l}\text { Safety, availability, } \\
\text { heritage }\end{array}$ \\
\hline Operation & $\begin{array}{l}\text { Intelligent } \\
\text { assets }\end{array}$ & & $\checkmark$ & $\begin{array}{l}\text { Safety, availability, } \\
\text { assurance }\end{array}$ \\
\hline Operation & $\begin{array}{l}\text { Removing } \\
\text { power } \\
\text { supplies }\end{array}$ & & $\checkmark$ & $\begin{array}{l}\text { Safety, availability, } \\
\text { carbon dioxide } \\
\text { reduction }\end{array}$ \\
\hline Operation & $\begin{array}{l}\text { Future- } \\
\text { proofing }\end{array}$ & $\checkmark$ & $\checkmark$ & $\begin{array}{l}\text { Safety, time, } \\
\text { assurance }\end{array}$ \\
\hline
\end{tabular}

\subsection{Diagnosis of cracking}

In the operational phase, CSIC has demonstrated on a multi-span masonry arch railway viaduct near Leeds, and also in London Bridge Station vaults, that sensing can be applied to diagnose deterioration mechanisms ahead of failure, and hence permit pro-active intervention (CSIC, 2018). This reduces safety risks and leads to savings by enabling planned intervention rather than reactive response. There are also benefits from the delaying of capital expenditure as a result of enabling replacement works to be pushed back in time. There is also reduced disruption to end users, leading to reputational benefit for the owner/operator and various secondary benefits for users.

\subsection{Intelligent assets}

For the operational phase, CSIC has proposed intelligent assets that sense their own performance, deterioration or failure, and are able to respond to their own condition by issuing requests for attention, or even initiating "self-maintenance" (ICE, 2017). A related proposition is intelligent assets that could issue warnings to other assets, for example, intelligent flood walls communicating with underground railway hatches. These yield benefits by reducing the cost and safety risks of human intervention for inspection or maintenance, avoiding potentially wasted routine inspection and maintenance activities; and avoiding the greater costs and other consequential effects of reactive maintenance to address worse deterioration or failure.

\subsection{Removing power supplies}

In the operational phase, CSIC has demonstrated the ability to harvest energy from bridge vibrations, for example, on the Forth Crossing, showing that low-energy sensors could be powered without batteries or external power supplies (ICE, 2017). This delivers benefits by avoiding the cost of cabling and the hazards of installing it, and the cost and safety risks of repeat visits to replace batteries, and overall, adds further to the potential effectiveness of intelligent assets.

\subsection{Information future proofing}

CSIC has developed techniques to improve "future-proofing" of asset information, for example, Liverpool Water Treatment Works (CSIC, 2015), anticipating the nature of information likely to be necessary for future management decision making, and valuemapping for prioritisation (CSIC, 2015). This delivers wideranging benefits to both future capex and future opex, including avoiding the costs of, for example, re-surveying assets to replace lost information, or accidents arising from the lack of design records and safety information.

\section{Other examples}

In this section, further examples are provided of how smart infrastructure creates benefits through the better use of existing assets (ICE 2017).

n "Smart" street-lighting by sensing approaching or departing movement of pedestrians or vehicles, to save energy cost and reduce carbon dioxide emissions, while preserving safety. 
Identifying and realising the benefits of smart infrastructure and construction Pocock
- Self-monitoring cathodic protection systems for corrosion control in bridges, for example, which yields benefits in reduced costs and improved safety by reducing the need for human visits for system monitoring and adjustment.

- More effective use of parking by sensing whether spaces are occupied and communicating where to find availability; hence, reducing circulation time spent hunting for spaces, leading to savings in journey time, congestion and carbon dioxide emissions.

- "Smart" motorways that detect rising traffic volumes and initiate hard-shoulder running to provide more capacity; hence reducing costs of delays and emissions from idling; and similarly, "tidal flow" mechanisms.

- Closer packing to (safely) realise more throughput by way of existing capacity, through connected intelligent road vehicles or the digital railway, yielding benefits by avoiding major capital expenditure of adding increased capacity by asset construction.

- Smart road cones that are able to detect when they are struck or move out of position; yielding benefits by improving the safety of road-workers.

\section{Cost avoidance}

Combining smart infrastructure technology with engineering knowledge of the expected behaviour, deterioration and failure patterns of assets, enables a cost-avoidance process. This process has been formalised to demonstrate substantial benefits of Smart Asset Management, for example, $£ 4$ million in cost avoidance alone, over 3 years at an industrial research facility (Uptime, 2018). The example shown in Figure 2 (Uptime, 2018), considers the condition of a typical air handling unit over time, as it deteriorates in service and passes progressively through the following stages to ever worse condition and more costly intervention.
- Post-commissioning re-alignment: $£ 250$ cost to re-align if picked up at an early stage.

- Misalignment detected by vibration: $£ 500$ cost to detect and re-align if predicted through sensing.

- Bearing damage detected by vibration: $£ 2000$ cost to detect, repair and re-align if predicted through sensing.

- Bearing failure: $£ 15000$ cost of emergency repairs including costs of expediting spare parts, due to reactive nature of this intervention.

- Shaft failure leading to loss of asset: $£ 45000$ cost to replace.

This can be described by Equation 1 (Uptime, 2018):

1. $\mathrm{CA}=\mathrm{OI}+\mathrm{R}-\mathrm{P}$

In summary, the estimated cost avoided as a direct result of a proactive maintenance action comprises the following components:

- operational impact if failure had occurred

- cost of reactive work not required

- (less the) cost of planned and scheduled repair

In use and at the heart of a smart asset management programme, this process entails not only identifying and proactively addressing a potential failure but also systematically estimating the cost components of Equation 1 and aggregating these on, for example, a monthly basis for management sign-off. This becomes a valuable element of demonstrating the benefits of adopting a smart proactive approach.

Further benefit is also often derived from the value of illustrating to senior management, at an early stage, the effectiveness of a strategic transformation programme.

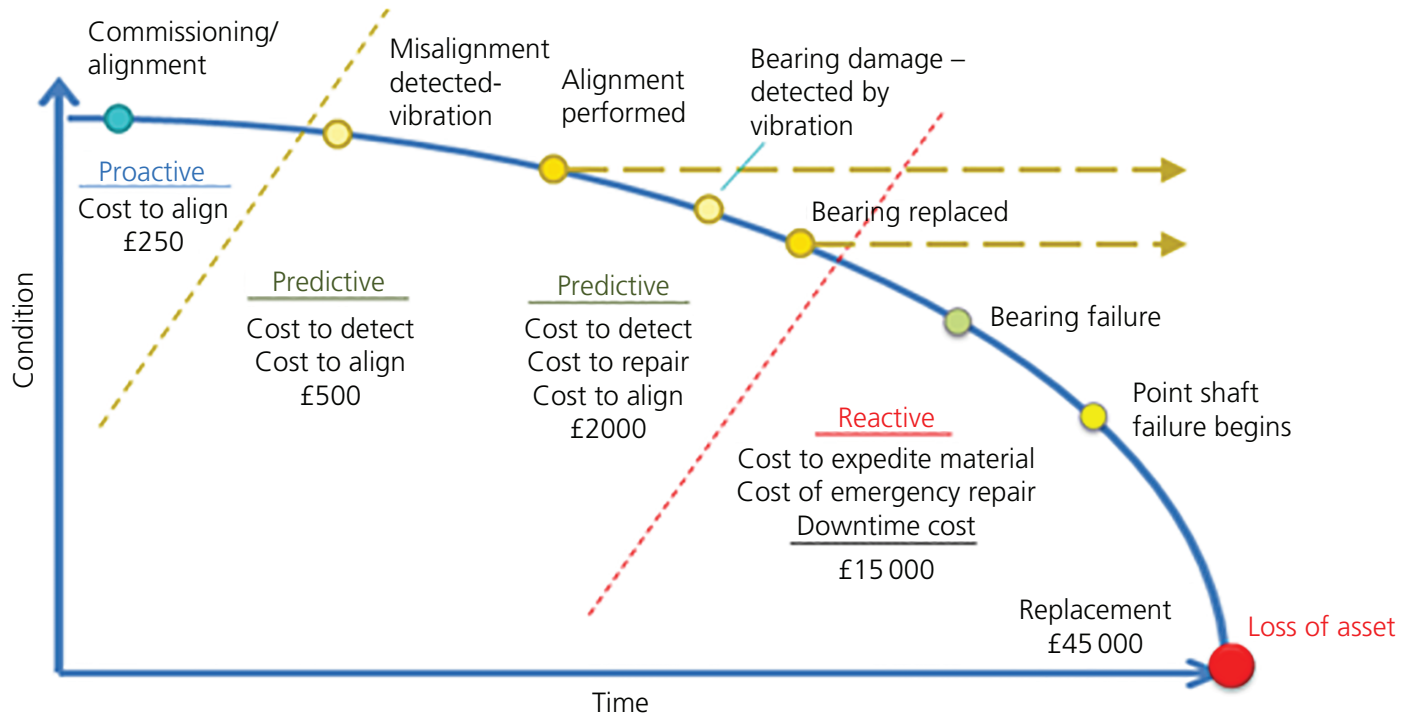

Figure 2. Example of cost avoidance concept 


\section{Benefits realisation}

\subsection{Establishing the business case}

The key issue is often one of recognising factors other than the technical effectiveness and elegance of the solution achieved through the research and development work. In the face of multiple conventional approaches, the developers of the new technique have to convince decision makers of the need for change.

\subsection{Business case structure}

A model for structuring a thorough and compelling business case is available through a simple Five Case Business Case process in accordance with conventional standards provided for in HM Treasury's Green Book. The five-case model ensures that the following elements are addressed:

- Fit with wider public policy objectives - the "Strategic Case";

- Providing value for money based on an economic appraisal the "Economic Case;

- Affordability, including capital and revenue - the "Financial Case";

- Flexibility of interventions - extent to which available intervention can be scaled up or down depending on the level of funding available - the "Commercial Case"; and

- Practical feasibility and implantation timeline - the "Management Case".

\subsection{Why use the five-case model?}

This is a well-established structure that is widely applied in the public sector including when making cases to Treasury; familiar to finance directors and their colleagues, so it brings advantages through familiarity and demonstrates a thoroughness of approach.

\subsection{Layers of potential benefits}

Potential benefits can be derived by different approaches including the following.

\subsubsection{Applying Lean techniques to deliver existing scope more efficiently}

A Lean practitioner can work through a range of techniques such as collaborative integrated planning workshops to identify and remove wasteful steps or ways of working, which may have developed by assembling an overall approach in haste or perhaps over a period of time in which existing practitioners have not recognised the trend towards less efficient working.

\subsubsection{Moving from reactive to planned maintenance to deliver the outcomes more effectively}

Maintenance practice demonstrates that outcomes such as availability or productivity are enhanced when an organisation increases the proportion of its total maintenance that is planned and scheduled, and reduces the proportion that is allowed to be delivered reactively (i.e. in response to clear indicators such as breakdowns or failures).

\subsubsection{Applying predictive techniques to deliver the outcomes by intervening earlier}

A further level of benefit can be achieved by intervening at an earlier stage and typically yielding cost avoidance savings as described above, based on approaches that enable early signs of deterioration to be identified, including expert knowledge, predictive testing, predictive analytics or asset monitoring by installed sensors.

\subsection{Exploring how much benefit might be achieved}

There is clearly a balance to be struck between the level of effort in developing the technology solution and the scale of the challenge it is trying to solve. As with any change programme, the potential benefit that can be realised in practice needs to be understood from an early stage in the solution development. Even a tremendous solution capability will not bring guaranteed benefits in every situation if poorly managed.

Together with the capability of the solution, the potential realisable benefit depends on the depth of the problem faced by the host organisation, the methods used in managing the change processes for implementing the solution, and the effectiveness of ongoing activities to support the new way of working after the implementation itself, aiming to ensure sustained success.

Opportunities for pilot or trial implementation offer and prove initial demonstrations of the potential benefit at a local scale.

External means should also be sought to add weight to a benefits claim based on those realised in pilot implementations, and hence a stronger proposition for a business case. Some industry sector organisations maintain benchmarking information that indicate typical levels of good, medium or poor performance for various parameters. Alternatively relevant literature can be surveyed, for example, a survey of conference papers and magazine articles from 2009 to 2015 (IAM, 2014; McGraw-Hill, 2013; Morrison, 2009; TRANSCO, 2011; Whitehall, 2015) on the implementation of asset management practices revealed c. 20 instances of $10 \%$ to $40 \%$ improvement in operating and maintenance costs, over $2-5$ years, which were assessed further and used to support making the case for an internal investment to enable the implementation of an asset management programme in the host organisation.

Specific case studies of close relevance to the proposed implementation can also provide strong supporting information. The example provided above to illustrate the concept of "cost avoidance" proved to be a valuable specific instance since it included not only cost avoidance but also made major improvements in the planned:reactive maintenance ratio (i.e. the second and third approaches identified above).

\subsection{Checklist}

The following checklist is proposed for use at an early stage in development to ensure there is recognition of key information that will be necessary to enable smart infrastructure technologies to be supported for implementation. 
Smart Infrastructure and Construction

Volume 172 Issue 4
Identifying and realising the benefits of smart infrastructure and construction

Pocock
What is going to be implemented?

- How it will deliver benefits.

- Benefits that can be quantified.

- How they will be quantified.

- Costs of implementing the change.

- How long it will take for the benefits to be realised and sustained (appraisal period)

- Model of benefits against costs over appraisal period.

- Summary of the findings.

\section{Conclusion}

A simple proposed framework is presented for identifying the benefits of smart infrastructure and construction, with descriptions of the potential direct and indirect sources, including both financial and non-financial benefits.

It is recommended that developers of smart infrastructure solutions assess at an early stage the potential benefits, how those benefits are derived and who realised such benefits. This is anticipated to assist in the preparation of more effective business cases for deployment.

Aside from the benefits derived during design and construction, there is considerable potential to deliver benefits in service. There is significant opportunity to avoid "opex" cost expenditure by combining smart infrastructure technology with engineering knowledge of the expected behaviour, deterioration and failure patterns of assets in service.

\section{Acknowledgements}

The author is grateful for the encouragement of the CSIC Steering Group and the CSIC International Advisory Committee to submit this paper, and to his colleagues at Jacobs whose works have helped in the development of this paper.

\section{REFERENCES}

Anderson (2018) See https://www.jacobs.com/news/144/deliveringinclusive-growth- $\% \mathrm{E} 2 \% 80 \% 93$-a-shared-responsibility (accessed January 2021).

CSIC (Centre for Smart Infrastructure and Construction) (2015) Annual Review. See https://www-smartinfrastructure.eng.cam.ac.uk/system/ files/documents/csic-annual-review-2015.pdf (accessed January 2021).

CSIC (2016) Annual Review. See https://www-smartinfrastructure.eng.cam. ac.uk/system/files/documents/csic-annual-review-2016.pdf (accessed January 2021).

CSIC (2017) Annual Review. See https://www-smartinfrastructure.eng.cam. ac.uk/system/files/documents/csic-annual-review-2017.pdf (accessed January 2021)

CSIC (2018) Annual Review. See https://www-smartinfrastructure.eng.cam. ac.uk/system/files/documents/csic-annual-review-2018.pdf (accessed January 2021).

CSIC (2019) See https://www-smartinfrastructure.eng.cam.ac.uk/ (accessed January 2021).

ICE (Institution of Civil Engineers) (2013) Realising a World-Class Infrastructure. ICE, London, UK.

ICE (2017) Intelligent Assets for Tomorrow's Infrastructure. Guidance Paper. ICE, London, UK.

IAM (Institute of Asset Management) (2014) Assets Magazine. IAM, London, UK.

McGraw-Hill (2013) Water Infrastructure 2013. Asset Management Smart Report. McGraw-Hill, New York, USA.

Morrison (2009) Asset management of Scotland's highways. In Proceedings of the Infrastructure Asset Management Conference, London, UK.

TRANSCO (2011) Asset management in Abu Dhabi transmission. In Proceedings of the GCC Power Conference.

Treasury (2020) See https://www.gov.uk/government/publications/thegreen-book-appraisal-and-evaluation-in-central-governent (accessed January 2021)

Uptime (2018) Recognised by Uptime Magazine as Best Overall Reliability Programme. NASA Langley Research Centre.

Whitehall (2015) Asset Master Plan Development at Scottish Water. In Proceedings of the Institute of Asset Management Conference, London, UK.

\section{How can you contribute?}

To discuss this paper, please email up to 500 words to the editor at journals@ice.org.uk. Your contribution will be forwarded to the author(s) for a reply and, if considered appropriate by the editorial board, it will be published as discussion in a future issue of the journal.

Proceedings journals rely entirely on contributions from the civil engineering profession (and allied disciplines). Information about how to submit your paper online is available at www.icevirtuallibrary.com/page/authors, where you will also find detailed author guidelines. 